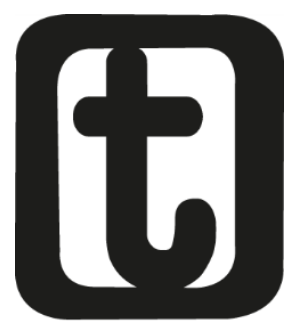

\title{
A FALSA DICOTOMIA ENTRE TEORIA E PRÁTICA
}

The false dichotomy between theory and practice

\section{Henrique Wellen ${ }^{1}$ Ranieri Carli ${ }^{2}$}

\section{RESUMO}

Analisa a relação entre teoria e prática no que concerne à atividade do assistente social. Tem como objeto tanto a falsa oposição entre ciência e política e suas consequências para o processo de trabalho dos assistentes sociais, quanto as correntes de pensamento que adotam esta oposição como um princípio filosófico. Analisa as teses do marxismo e do positivismo, assim como as suas posições diante de questões como a neutralidade, a prática política, a cientificidade do pensamento, e outros aspectos do problema.

\section{PALAVRAS-CHAVE}

Teoria. Prática. Marxismo. Positivismo. Serviço Social.

\footnotetext{
Graduado em Administração de Empresas pela UFPB, Graduado em Administração Pública pela UFPB, Mestre em Administração (com habilitação em Gestão e Políticas Públicas) pela UFRN, Doutor em Serviço Social pela UFRJ, Professor adjunto da Universidade Federal do Rio de Janeiro. E-mail: <harw@uol.com.br>.

${ }^{2}$ Graduado e mestre em Ciências Sociais pela UERJ; Doutor em Serviço Social pela UFRJ; Professor adjunto da Universidade Federal Fluminense no Pólo Universitário de Rio das Ostras. E-mail: <raniericarli@gmail.com>.
}

Temporalis, Brasilia (DF), ano 10, n.20, p.113-135, jul./dez. 2010. 


\section{tempordils}

WELLEN, H.; CARLI, R. A FALSA DICOTOMIA ENTRE TEORIA

\section{ABSTRACT}

Analyzes the relationship between theory and practice in regard to social activity. We object to both the false opposition between science and policy and its consequences for the working process of social workers, as the currents of thought that take this opposition as a philosophical principle. Analyzes the theses from Marxism and positivism, as well as their positions on issues such as neutrality, political practice, the scientific thought, and other aspects of the problem.

\section{KEYWORDS}

Theory. Practice. Marxism. Positivism. Social Work.

Submetido em 14/03/2011

Aceito em 23/05/2011

\section{INTRODUÇÃO}

A intenção deste artigo é problematizar a relação entre teoria e prática, especificando a correlação de tais categorias na atuação do assistente social.

É nosso propósito colocar em discussão as principais correntes filosóficas que nortearam a atuação laica do serviço social no Brasil - nomeadamente o positivismo e o marxismo -, para analisar como abordam a problemática anunciada.

Para nosso objetivo, buscamos, inicialmente, apresentar a temática de uma maneira mais ampla e abstrata, e, no momento seguinte, procuramos dar enfoque a questões mais concretas.

Desde os pré-socráticos, jamais o pensamento social separou em dicotomias tanto a prática quanto a teoria. Tal fato marca, de maneira explícita, várias exposições teóricas, como é o caso, por exemplo, da República de Platão. É nessa obra que o autor grego 


\section{temporalis}

WELLEN, H.; CARLI, R. A FALSA DICOTOMIA ENTRE TEORIA

alega a necessidade de dois requisitos para que a justiça seja um bem comum, plenamente realizável e realizada: a existência de seres humanos justos e de um Estado justo (PLATÃO, 2006, p. 201).

Uma vez que, para o autor, o Estado justo seria uma consequência natural da relação social entre seres humanos justos, torna-se imperiosa a preocupação com a educação e formação de todos os integrantes da polis. Vale frisar que, no que concerne às partes integrantes de uma formação plena, o nosso filósofo é cristalino: a educação consiste tanto em atividades físicas, como a ginástica, quanto em atividades para a alma, relacionadas com as diversas expressões culturais, tais como as artes imitativas (o teatro), a interpretação musical e as várias formas de poesia, literatura e filosofia (PLATÃO, 2006, p. 115). A formação dos seres humanos justos requer, portanto, um profundo conhecimento teórico que balize as práticas cotidianas.

Buscando apresentar, por meio de diálogos, o aprendizado advindo do contato com o seu mestre Sócrates, Platão intentou, ao longo de toda a sua vida, analisar criticamente sua sociedade para que seus integrantes pudessem alcançar níveis maiores de participação política e comprometimento social. Por isso que, conforme elucida Heller (1998, p. 68), podemos afirmar que "[...] a vida inteira de Platão constitui uma luta teórica e prática pela renovação da polis, pela restauração da comunidade orgânica e da ética comunitária".

Apenas com o positivismo pós-1848 a rígida separação entre teoria e prática colocou-se na pauta do dia. Existe, certamente, um positivismo anterior a este período, participante da revolução burguesa, que, em face desta circunstância, não produzia a mencionada dicotomia. A propósito, Jean Baptiste Condorcet, representante desse positivismo revolucionário, ao projetar os resultados da revolução francesa, da qual participa, ressalta que as

Temporalis, Brasilia (DF), ano 10, n.20, p.113-135, jul./dez. 2010. 


\title{
tempordils
}

WELLEN, H.; CARLI, R. A FALSA DICOTOMIA ENTRE TEORIA

sociedades futuras verão "[...] a destruição da desigualdade entre as nações; os progressos da igualdade em um mesmo povo; enfim, o aperfeiçoamento real do homem" (CONDORCET, 1988, p. 266).

Löwy (2003, p. 20) explica qual é a relação entre ciência e prática existente em Condorcet (1988):

\begin{abstract}
Este ideal de ciência neutra, tão imune aos 'interesses e paixões' quanto a física ou a matemática, estará no coração da problemática positivista durante dois séculos. Mas, há ainda em Condorcet uma significação utópico-crítica: seu objetivo confesso é o de emancipar o conhecimento social dos 'interesses e paixões' das classes dominantes. O cientificismo positivista é aqui um instrumento de luta contra o obscurantismo clerical, as doutrinas teológicas, os argumento de autoridade, os axiomas a priori da Igreja, os dogmas imutáveis da doutrina social e política feudal (LÖWY, 2003, p. 20)
\end{abstract}

Há, dessa maneira, num filósofo típico como Condorcet (1988), a união fecunda entre ciência e prática.

Nenhum iluminista alocou em esferas isoladas os saberes e os poderes. Um dos maiores pensadores, o idealista alemão Fichte, determinou o conteúdo prático de suas ideias filosóficas: "[...] toda ciência é fundamento de ação; uma ciência vazia, sem nenhuma referência à prática, não há" (FICHTE, 1973, p. 173). Assim, inexiste um saber neutro, desinteressado. A ciência é sempre instrumento para a ação prática.

\section{O MARXISMO E A CRÍTICA ÀS DICOTOMIAS}

O marxismo herda o pensamento progressista da burguesia revolucionária. Porém, desta vez, a união entre a prática e a teoria 


\section{temporolis}

WELLEN, H.; CARLI, R. A FALSA DICOTOMIA ENTRE TEORIA

se dá no contexto da revolução proletária. Com a ordem burguesa instaurada, o papel de sujeito revolucionário é assumido pela classe trabalhadora.

Como a classe dominante visa a perpetuar-se enquanto tal, o desenvolvimento histórico gerado dentro da sociedade burguesa não produziu apenas avanços, mas também grandes limitações humanas e produtivas. Esses obstáculos demonstram que “[...] o sistema burguês tornou-se demasiado estreito para conter as riquezas criadas em seu seio [...]"3 (MARX (1990, p. 24). Isso explicita não somente o caráter repressivo e conservador da burguesia, mas especialmente que a importância do proletariado encontra-se na relação dialética entre incorporação e superação das conquistas existentes na sociedade burguesa:

O marxismo conquistou a sua significação histórica universal como ideologia do proletariado revolucionário porque não repudiou de modo algum as mais valiosas conquistas da época burguesa, mas, pelo contrário, assimilou e re-elaborou tudo o que houve de valioso em mais de dois mil anos de desenvolvimento do pensamento e da cultura humanos (LÊNIN, 1980, p. 398).

Voltaremos ainda a este ponto, mas o importante é o que se segue: agora é Marx (1990) quem fala em união entre a ciência e a política.

3 É por isso que, ao referir-se à primeira experiência social em que os trabalhadores estiveram no controle do Estado, Marx apreendeu a condição fundamental de destruição desses obstáculos que restringem e limitam o desenvolvimento da sociedade: "[...] eis como Marx resumia as tarefas da classe operária revolucionária, no tempo da Comuna de Paris: 'Ela não tem um ideal a realizar; tem apenas de libertar os elementos da nova sociedade, tal como eles se encontram já desenvolvidos no seio da sociedade burguesa em vias de dissolução' " (LUKÁCS, 1991, p. 186). 


\section{temporalis}

WELLEN, H.; CARLI, R. A FALSA DICOTOMIA ENTRE TEORIA

Contudo, esta união põe-se num nível historicamente mais amplo do que aquele visto entre os iluministas (FICHTE, 1973; CONDORCET, 1988 e outros), uma vez que o proletariado porta a possibilidade de se emancipar humanamente a sociedade, superando a emancipação apenas política da revolução burguesa ${ }^{4}$.

A última das teses sobre Feuerbach coloca em evidência as determinações deste contexto. É famosa a afirmação de Marx que os filósofos até então apenas interpretaram da realidade; seria preciso agora modificá-la (MARX; ENGELS, 2006). Percebam que Marx fala de filósofos a transformar o estado de coisas; os intelectuais, que se encontrassem a cargo da produção de ideias, estariam, na mesma medida, chamados a participar da transformação. Marx não exclui das tarefas dos teóricos a transformação prática das relações sociais instituídas (MARX ; ENGELS, 2006).

Nesse sentido, um invólucro de suposta neutralidade científica serve apenas para que pensadores que defendem o ordenamento social vigente se isentem de responsabilidade e crítica sociais. Não obstante, para usar as vestes da imparcialidade, deve-se adquirir um elemento típico da ideologia liberal: o descomprometimento com a comunidade em que se está inserido.

Para expor esse pensamento, não foi preciso apenas que Marx apresentasse uma posição crítica dentro do contexto social em que vivia, mas que conseguisse propor uma análise teórica revolucionária. À medida que soube apreender os elementos mais

\footnotetext{
${ }^{4}$ Mesmo autores que não tiveram uma ligação estreita com a tradição marxista apreenderam a condição histórica de emancipação do proletariado e seu papel de classe revolucionária. Tal é o caso de Merleau-Ponty (2006) ao analisar o proletariado como sujeito e objeto de sua própria filosofia da história.
} 


\section{temporolis}

WELLEN, H.; CARLI, R. A FALSA DICOTOMIA ENTRE TEORIA

avançados de grandes pensadores - como Adam Smith, David Ricardo, Ludwig Feuerbach e Hegel -, Marx propôs uma superação de toda essa herança:

Até a filosofia clássica alemã, a filosofia foi concebida
como atividade receptiva ou, na melhor hipótese,
ordenadora; isto é, foi concebida como
conhecimento de um mecanismo que funciona
objetivamente fora do homem. A filosofia clássica
alemã introduz o conceito de 'criatividade' do
pensamento, mas em um sentido idealista e
especulativo. A que parece, somente a filosofia da
práxis realizou um passo à frente no pensamento,
sobre a base da filosofia clássica alemã, evitando
qualquer tendência ao solipsismo, historicizando o
pensamento na medida em que o assume como
concepção de mundo, como 'bom senso' difuso na
multidão (e esta difusão não seria concebível sem a
racionalidade ou a historicidade) e difuso de tal
maneira que possa converter-se em norma ativa de
conduta (GRAMSCl, 1988, p. 33 , grifos originais).

Ainda que o tenha utilizado por necessidades operacionais, decorridas de sua situação prisional, Gramsci é extremamente bem-sucedido ao definir o marxismo como filosofia da práxis. Isso porque, mediante esse termo, o autor italiano consegue transmitir uma condição inalienável da tradição teórica, metodológica e política inaugurada por Marx: a indissociabilidade da teoria com a prática, ou da ciência com a política.

Todavia, Gramsci (1988) não foi o único a expor teoricamente esse pressuposto do marxismo. Com estas palavras de História $e$ consciência de classe, Lukács (2003, p. 64- 65) resume o sentido destas noções para o marxismo: 


\section{temporolis}

WELLEN, H.; CARLI, R. A FALSA DICOTOMIA ENTRE TEORIA

A dialética materialista é uma dialética revolucionária. Essa determinação é tão importante e de um peso tão decisivo para a compreensão de sua essência, que, antes mesmo de discorremos sobre o método dialético em si, temos de entendê-la para abordarmos o problema de forma correta. Trata-se aqui da questão da teoria e da prática, e não somente no sentido em que Marx a entendia em sua primeira crítica hegeliana quando dizia que a 'teoria torna-se força material desde que se apodere das massas'. Trata-se, antes, de investigar, tanto da teoria como na maneira como ela penetra nas massas, esses momentos e essas determinações que fazem da teoria, do método dialético, o veículo da revolução; trata-se, por fim, de desenvolver a essência prática da teoria a partir da teoria e da relação que estabelece com seu objeto (LUKÁCS, 2003, p. 64- 65).

A primeira frase da citação é lapidar: "[...] a dialética materialista é uma dialética revolucionária” (LUKÁCS, 2003, p.64). Assim como foi a dialética hegeliana para a burguesia revolucionária, a dialética de Marx é um veículo para a revolução proletária, tendo em vista que, com este método, a classe trabalhadora é elevada à consciência das contradições da sociedade capitalista. E, afastando de uma vez por todas qualquer sombra de dicotomias, Lukács (2003) deixa claro que a intenção do marxismo é a de desenvolver na teoria o seu caráter prático, ou, como ele disse literalmente, "[...] de desenvolver a essência prática da teoria a partir da teoria e da relação que estabelece com seu objeto" (LUKÁCS, 2003, p.64-65).

Adiante, Lukács (2003, p.97) continua o argumento: “[...] a unidade da teoria e da práxis é, portanto, apenas a outra face da situação social e histórica do proletariado". A situação social do proletariado impõe que a totalidade das relações capitalistas seja compreendida: "[...] do ponto de vista do proletariado, o autoconhecimento coincide com o conhecimento da totalidade; 


\section{temporolis}

WELLEN, H.; CARLI, R. A FALSA DICOTOMIA ENTRE TEORIA

ele é, ao mesmo tempo, sujeito e objeto do seu próprio conhecimento".

Além disso, há algo mais: ao lado da imbricação entre a ciência e a política, Marx sempre afirmou que as categorias do saber são condições da prática humana. Esta é uma outra dimensão do tema. As categorias abstraídas por Marx não são elucubrações sem calço no real; ao contrário, são criadas pela prática social. Valor de uso e de troca, trabalho abstrato e concreto, etc., são produtos da atividade dos homens e não conceitos ideais, desprovidos de concretude. Trata-se de uma outra esfera da imbricação entre teoria e prática.

Perceba-se, por exemplo, a categoria da totalidade em si mesma. Segundo Lukács (2003), é precisamente esta categoria o diferencial entre Marx e as ciências burguesas ${ }^{5}$. Pois a totalidade não é um produto ideal, um construto teórico de Marx, senão uma condição da própria existência: as relações humanas são um conjunto inesgotável de modalidades de interação, como a economia, o Estado, a família, o trabalho, a educação, a cultura, a arte etc. A vida

\footnotetext{
${ }^{5}$ Como explica Netto (2004, p. 107; grifos originais), foi a partir da categoria da totalidade que Marx conseguiu desenvolver grande parte de suas análises sobre o Modo de Produção Capitalista: "Ora, sobre que fundamento se efetivam essas descobertas? Sobre o fundamento da mais central das determinações de Marx, aquela que já se apresenta na Miséria da filosofia: a determinação de que as instâncias constitutivas da sociedade se articulam numa totalidade concreta e são postas geneticamente pelo primado ontológico das relações econômicas. Não se trata, como sempre quiseram o marxismo vulgar e os antagonistas de Marx, de reduzir a teoria social de Marx a uma teoria fatorialista, com o primado do 'econômico'; nada disto: o primado ontológico da economia, que funda a teoria social moderna, descoberto por Marx, opera no interior de uma estrutura teórica que reproduz teoricamente o objeto real na perspectiva da totalidade".
}

Temporalis, Brasilia (DF), ano 10, n.20, p.113-135, jul./dez. 2010. 


\section{temporalis}

WELLEN, H.; CARLI, R. A FALSA DICOTOMIA ENTRE TEORIA

individual de cada membro da humanidade constitui-se destas interações; é uma totalidade particular de relações.

Neste sentido, ao afirmar que as categorias são formas do ser, condições da existência (MARX, 2001), Marx consegue elevar a um nível mais amplo a conexão entre prática e teoria: tudo o que a teoria reflete está enraizado nas práticas sociais; a teoria é, de fato, o reflexo das práxis humana ${ }^{6}$, em seus diversos momentos. É por isso que Marx argumentava em duas das Teses sobre Feuerbach que a prática é o critério da verdade teórica, e que todos os mistérios da vida social são resolvidos na prática (MARX; ENGELS, 2006). Qualquer discussão sobre a veracidade de determinada categoria é puramente escolástica, se não se leva em conta a prática. Marx poderia afirmar a pertinência da categoria da totalidade, mas, caso a totalidade não fosse uma forma do ser social, as afirmações marxianas se perderiam no vazio; teriam um caráter de simples escolástica, carente de conteúdo.

Para testar qualquer teoria ou representação do real, é inevitável apelar para o mesmo elemento: a própria realidade. E, como pressuposto desta última, a prática humana não apenas transforma a realidade, como é o lastro de qualquer elucubração. Como afirmou Engels (1986, p. 289; grifos originais), a prova para toda teoria encontra-se na sua relação com a prática social:

[...] os homens, antes de argumentar, haviam atuado. Im Anfang war die Tat $^{7}$. E a ação humana havia resolvido a dificuldade muito antes de os sofismas humanos a inventarem. The proof of de pudding is in

\footnotetext{
${ }^{6}$ Para uma análise mais ampla sobre a Práxis, delineando o sentido desse termo em pensadores tais como Hegel, Sartre, Kierkegaard, Peirce e Dewey ver Bernstein (1971). Para uma análise histórica da Práxis, desde Aristóteles até Marx ver Lobkowicz (1967).

${ }^{7}$ No começo, era a ação. Palavras de Goethe, citadas em Fausto.
} 


\section{temporolis}

WELLEN, H.; CARLI, R. A FALSA DICOTOMIA ENTRE TEORIA

the eating ${ }^{8}$. Desde o momento em que aplicamos essas coisas, de acordo com as qualidades que percebemos nelas, a nosso uso próprio, submetemos as percepções de nossos sentidos a uma prova infalível no que se refere à sua exatidão ou à sua falsidade (ENGELS, 1986, p. 289).

\section{O POSITIVISMO: A CIÊNCIA E A PRÁTICA COMO DUAS VOCAÇÕES DISTINTAS}

Uma outra abordagem encontra-se no positivismo que se lê nas obras de autores burgueses pós-1848. Neste período, a ordem burguesa já está consolidada e a classe trabalhadora aparece como novo sujeito revolucionário. A burguesia torna-se conservadora. Aquele positivismo de Condorcet (1988) é despido de sua natureza transformadora.

A relação entre teoria e prática ganha feição dicotômica. Se antes, para Condorcet (1988), a prática era um momento constitutivo da teoria, agora, exclui-se da teoria o âmbito prático, de intervenção nas relações postas. É certo que há uma prática, embora se negue a sua existência: trata-se de uma prática conservadora, contrarrevolucionária.

Durkheim (1975, p. 104) soube expressar esta dicotomia: "[...] a ciência só aparece quando o espírito, abstraindo toda a preocupação prática, aborda as coisas com o único fim de ter representações delas". A ciência então abstrai toda preocupação prática, para estudar as coisas com o único propósito de efetivamente representá-las. A preocupação prática não apenas é indesejável, como na mesma medida é o fim da ciência. Quando cai

${ }^{8}$ Prova-se o pudim comendo-o.

Temporalis, Brasilia (DF), ano 10, n.20, p.113-135, jul./dez. 2010. 


\section{tempordils}

WELLEN, H.; CARLI, R. A FALSA DICOTOMIA ENTRE TEORIA

na prática, a ciência passa a não mais merecer o desígnio de ciência, diria Durkheim.

O sociólogo francês até mesmo utiliza a dicotomia entre ciência e política para explicar a razão pela qual a sociologia nasceu tardiamente entre as ciências da natureza e da sociedade. Para ele, as revoluções exigiam que a atividade prática estivesse em primeiro plano, o que implica deixar de lado os propósitos puramente científicos da ciência. Assim, enquanto perduraram as tentativas revolucionárias, os homens não se empenharam tanto em pesquisas sociológicas. Terminado o período revolucionário, Durkheim (1975) argumenta que a ciência pode ocupar o lugar central das preocupações humanas:

Podemos certamente concluir, não sem razão, que a vida que [...] se desenvolveu [em meados do século XIX] é muito agitada e não deixa de ter lamentáveis desperdícios de forças. Mas, enfim, é a vida. Que ela se discipline e se regularmente, que os ânimos assim despertos, em vez de se consumirem sem método, se agrupem e se organizem, que cada um meta mãos a uma tarefa definida, e é-nos permitido esperar que este movimento figurará na história das idéias em geral e da sociologia em particular (DURKHEIM, 1975, p. 122).

Sem os "[...] lamentáveis desperdícios de forças [...]" que uma revolução demanda, a ciência disciplinada e metódica pode se desenvolver, não desviando sua atenção com as agitações peculiares da prática. Por certo, Durkheim (2007, p. 15; grifos originais) não teria assim escrito caso não entendesse a teoria e a prática como instâncias excludentes, como fica explícito ao defender em As Regras do Método Sociológico que "[...] a primeira regra e a mais fundamental é considerar os fatos sociais como coisas". 


\section{temporolis}

WELLEN, H.; CARLI, R. A FALSA DICOTOMIA ENTRE TEORIA

Um positivista neokantiano como Max Weber está de acordo com o positivismo clássico de Durkheim no que tange à separação entre teoria e prática. São de sua letra as seguintes palavras: “[...] jamais pode ser tarefa de uma ciência empírica proporcionar normas e ideais obrigatórios, dos quais se possa derivar 'receitas' para a prática" (WEBER, 1999, p. 109). Para Weber, não se deve buscar na teoria as “[...] receitas [...]" para a ação porque são vocações de natureza distinta. É nesse sentido preciso que o autor alemão não somente se enquadra dentro da matriz positivista, como é referência decisiva para o seu desenvolvimento:

Max Weber não deveria ser considerado como um autêntico sociólogo positivista; suas concepções metodológicas são bastante distantes do positivismo e, em certos aspectos, diretamente contraditórias em relação a ele. Mas sobre um ponto capital - que é precisamente o que nos interessa neste livro - há uma convergência entre sua teoria da ciência e a teoria dos positivistas: o postulado da neutralidade axiológica das ciências sociais. Na realidade, foi ele quem formulou o postulado de forma precisa e sistemática, mais rigorosa que os vagos desejos dos positivistas do século XIX (LOWY, 2003, p. 103, grifos originais).

As teses destes autores giram em torno do mito da neutralidade. É o ideal positivista da ciência neutra, inspirado nas ciências naturais (o que, aqui, diz respeito mais a Durkheim do que a Weber). Assim como um biólogo não toma partido nem a favor nem contra as células, um sociólogo ou um assistente social não deveria assumir uma posição política diante da questão social ou de qualquer outro objeto de estudo. Este mito da neutralidade axiológica pressupõe que a atitude das ciências naturais poderia ser a mesma vista nas ciências sociais, como se seus objetos fossem similares. Como diz Lukács (2009), a escolha pela neutralidade já implica uma tomada de posição em face das lutas sociais. 


\section{tempordils}

WELLEN, H.; CARLI, R. A FALSA DICOTOMIA ENTRE TEORIA

Porém, a pretensa neutralidade da ciência perante a prática política não é fora de propósito; isto é, possui uma razão de ser. Tanto Durkheim quanto Weber pertencem à geração de pensadores burgueses em que a unidade entre ciência e política é perigosa, uma vez que é o proletariado que está em condições de realizar esta união na sua atividade, como já vimos. Não apenas os sociólogos estiveram à frente deste processo de separação dicotômica entre saber e poder, mas também autores de outras disciplinas, como a economia, por exemplo. É o tempo em que a economia deixa de ser economia política para ser somente economia, pura e simples, imaculada nas academias. Walras (1983) representou este processo com os dizeres a seguir:

A arte 'aconselha, prescreve, dirige' porque tem
como objeto os fatos que têm sua origem no
exercício da vontade humana e, sendo a vontade
humana, pelo menos até certo ponto, uma força
clarividente e livre, cabe aconselhá-la, prescrever-lhe
tal ou qual conduta, dirigi-la. A ciência 'observa,
expõe, explica' porque tem como objeto fatos que
têm sua origem no jogo das forças da Natureza e,
sendo as forças da Natureza cegas e fatais, não há
outra coisa a fazer com elas além de observá-las e
explicar seus efeitos (WALRAS, 1983, p. 16).

A ciência observa, expõe e explica, enquanto que a arte (isto é, a atividade política) aconselha, prescreve e dirige. Como se vê, Walras (1983) concorda com Weber (1999) e Durkheim (1975; 2007) a respeito da dicotomia ora estudada: pretensamente, não haveria função prática no âmbito da ciência, sendo este último o lugar da mera observação e descrição das forças da Natureza. 


\section{temporalis}

WELLEN, H.; CARLI, R. A FALSA DICOTOMIA ENTRE TEORIA

\section{CONCLUSÃO}

É peculiar ao marxismo que cada circunstância concreta demande uma modalidade de análise particular. Cada época produz as suas categorias particulares. Transpondo esta ideia para a intervenção do Serviço Social, significa que cada momento singular exigirá um método, uma intenveção, uma teoria à sua maneira, com mediações particulares. Para o positivismo, existe um método descolado da prática; é um método universal cuja validade se estenderia para todo e qualquer fato social, não importa a sua peculiaridade; são regras do método sociológico em abstrato.

Trazendo esse debate para o âmbito específico do Serviço Social, é inegável afirmar que a unidade entre teoria e prática é um elemento constitutivo da atuação do Serviço Social. Que se pense, por exemplo, em uma categoria como a totalidade (e não é à toa que justamente esta categoria nos serviu de ilustração acima para a conexão entre consciência e objeto a ser conhecido). A análise de determinada demanda de qualquer trabalhador em um dos serviços sociais há de levar em conta sempre a categoria da totalidade, a saber, o conjunto amplo de relações em que este indivíduo está inserido: relações trabalhistas (desemprego, emprego precário, com benefícios ou não, terceirizado etc.), políticas (sindicato, partido, ideologias etc.), familiares (relações entre gênero, gerações etc.) e assim por diante.

Mesmo sabendo que uma abordagem teórica plena da totalidade social será uma tarefa inalcançável, é somente a partir dessa premissa que se pode afugentar um caminho mistificador da realidade, que fragmenta as esferas que a compõem e que individualiza os problemas sociais. Como adverte Lênin (apud LUKÁCS, 1978, p. 40; grifos originais), mesmo não a alcançando plenamente, somente a tentativa de vinculação das esferas sociais, 


\title{
tempordils
}

\author{
WELLEN, H.; CARLI, R. A FALSA DICOTOMIA ENTRE TEORIA
}

a partir de uma perspectiva que almeje a universalidade, nos afasta de erros pré-meditados:

\begin{abstract}
Para se conhecer realmente um objeto, é necessário apreender e analisar todas as suas facetas, todas as relações contextuais e 'mediações'. Nunca o conseguiremos plenamente, mas a exigência da universalidade preservar-nos-á do erro e de cristalização 9 (LÊNIN apud LUKÁCS, 1978, p. 40).
\end{abstract}

Por outro lado, quando se promove o desligamento teórico desses nexos sociais e se adota uma perspectiva positivista de parcelamento da realidade experimentada pelos usuários dos serviços de assistência, a atuação do assistente se empobrecerá em grande medida.

Como vimos, Émile Durkheim (1975; 2007) - exemplar de destaque dessa matriz teórica - contribuiu decisivamente para a disseminação de posturas que fragmentam a realidade social em campos desconexos. No que concerne ao Serviço Social, suas

\footnotetext{
${ }^{9}$ Vale salientar que a totalidade social não pode ser igualada a uma postura meramente formal de que vincula as esferas sociais, mas que descarta seus momentos ontológicos e suas relações de interdependência. No caso da economia, temos um exemplo elucidativo: “Conclusão: a totalidade clássica é apenas totalidade formal. Formal porque o trabalho não é apreendido como substância que, subordinada ao capital enquanto um dos seus momentos, como vai entender Marx, é elevada à condição de sujeito; sujeito que tem, em si próprio, a lei interna de seu movimento. Conclusão: a totalidade analítica é meramente formal; é tão-somente totalidade da ordem do pensar e não totalidade que é também engendrada pelo movimento do real. Por isso, os clássicos não puderam chegar ao conceito de capital como totalidade viva, mas unicamente como totalidade entendida tal qual agregado de coisas físicas: máquinas, matérias-primas, instalações etc. Daí a confusão que se meteu a economia para precisar que elementos da riqueza social poderiam ser classificados como capital" (TEIXEIRA, 2004, p. 71-72).
} 


\section{temporolis}

WELLEN, H.; CARLI, R. A FALSA DICOTOMIA ENTRE TEORIA

obras inspiram a análise da questão social a partir de uma dupla condição interventiva: uma moralização da questão social, tratando-a como disfunção da coesão social, e uma tendência à psicologização dos problemas sociais. Segundo Netto (2005, p. 47, grifos originais), esse tratamento teórico, de uma “[...] psicologização que se forja em Durkheim [...]", desvia da apreensão do "[...] conjunto macroscópico da "questão social [...]" para instaurar uma "[...] evidência societária das suas refrações mais preocupantes para o pensamento conservador: o problema da coesão social".

Na mesma linha, outra destacada pesquisadora do Serviço Social adverte para os problemas que acompanham essa perspectiva:

A proposta de reforma moral durkheimiana, de criação de vínculos que garantam uma solidariedade que seja princípio diretor da ação dos homens, tem sido, ao longo da história, objetivo precípuo das instituições, práticas sociais e profissionais sob o capitalismo. $\mathrm{O}$ entendimento das questões políticas (sobretudo a luta de classes) como um problema de coesão social, de vinculação dos indivíduos a valores e normas coletivas, metamorfoseia os aspectos políticos em éticos, cuja responsabilidade passa a ser atribuída à sociedade civil. A esses traços acresce-se a necessidade de uma ação social de conteúdo pedagógico, mediante procedimentos técnicos racionais, e teremos a fórmula dukheimiana que tem sido utilizada na despolitização das questões sociais, na reprodução ideológica da sociedade pela via da moral, esta, instrumento privilegiado para assegurar a coesão social (GUERRA, 2005, p. 64-65, grifos originais).

Quando analisamos as principais correntes filosóficas que norteiam a atuação laica do Serviço Social brasileiro, podemos perceber a contínua presença de uma dualidade, pois tanto o marxismo como

Temporalis, Brasilia (DF), ano 10, n.20, p.113-135, jul./dez. 2010. 


\section{temporalis}

WELLEN, H.; CARLI, R. A FALSA DICOTOMIA ENTRE TEORIA

o positivismo estão bastante arraigados na intervenção do assistente social no Brasil. Em cada uma, vê-se uma interpretação distinta da unidade entre teoria e prática, o que significa que cada uma norteará de modo diverso a sua intervenção. É de se notar que haja um viés de forte conservadorismo no serviço social brasileiro atualmente, com a influência de determinadas correntes da chamada pós-modernidade, segundo afirma Santos (2000).

Não obstante, essa dualidade possui contornos teóricos, mas expressa uma derivação da prática e da estrutura que sustenta o Serviço Social. Existe uma determinação que marca o nascimento da prática do assistente social, isto é, a sua relação com o Estado e na sua função domesticadora das revoltas sociais. É por isso que o esforço pela utilização de um referencial crítico baseado em postulados marxistas não representa apenas uma luta teórica, mas, acima de tudo, um embate político.

A história do Serviço Social no Brasil apresenta disputas e lutas em torno dessa temática, ora apresentando o assistente social como um cumpridor das regras estabelecidas e o distanciando de uma reflexão crítica entre teoria e prática, ora não apenas problematizando essa relação, como também tencionando uma tomada de posição frente à realidade que determina sua profissão.

Mesmo com grandes impactos da chamada pós-modernidade sobre pesquisas e estudos no interior do pensamento acadêmico, no caso do serviço social brasileiro tais imposições foram atenuadas por uma certa herança teórica e política. Devido a um importante processo de debates e reflexões em torno da função e do papel do assistente social, pôde-se romper tanto com uma visão ordenadora da sociedade, como se proteger de conjecturas que mistificam a realidade: 


\section{temporolis}

WELLEN, H.; CARLI, R. A FALSA DICOTOMIA ENTRE TEORIA

Entretanto, pelo acúmulo das elaborações profissionais do que noutro lugar denominarei de intenção de ruptura, e sobretudo pela majoritária posição sócio-ocupacional dos assistentes sociais, o neoconservadorismo pós-moderno foi menos ponderável nessa área do que em outros campos das ciências sociais (NETTO, 2005, p. 11).

Pode-se observar que, como resultado de uma expressiva história de debates, especialmente a partir do segundo lustro da década de 1980, o Serviço Social constitui-se como um campo de saber privilegiado para a análise entre teoria e prática social e, em especial, nas relações desses complexos com as determinações do sistema capitalista.

É possível destacar que o Código de 1993 - como continuação e superação do Código de 1986 - avança na tentativa de vincular diretamente a teoria e a prática social, demarcando o terreno ideológico num sentido preciso: se afastando tanto de matizes conservadoras que por longo tempo hegemonizaram o Serviço Social, como desprivilegiando posturas meramente abstratas, de caráter idealista, ou pós-modernas, que muitos ecos promovem hoje em dia na universidade.

Ao centrar esforços na análise da interface entre ética e Serviço Social, uma das suas mais importantes pesquisadoras expõe não somente a necessidade de vinculação direta entre teoria e prática, como a tomada de posição política frente à ordem societária estabelecida:

[...] compreender que a ética não leva à superação da alienação, pois nos termos da concepção que informa nosso Código, tal superação implica a ruptura com a ordem social burguesa em sua totalidade. No entanto, isso não significa afirmar que a ética não tem 


\section{tempordils}

WELLEN, H.; CARLI, R. A FALSA DICOTOMIA ENTRE TEORIA

nenhuma função nesta sociedade de classes, que ela só reproduz a alienação. Sua principal função é a de estabelecer a crítica radical à moral do seu tempo, fornecendo elementos para a compreensão dos impedimentos à sua livre manifestação (BARROCO, 2004, p. 193).

No interior do Serviço Social, posições como estas instauram caminhos de ampla responsabilidade aos assistentes sociais, pois dimensionam a necessidade de seu preparo para a intervenção política e social. O ganho cognoscitivo é que, ao se adotar tais posições teóricas, afastam-se conjecturas reacionárias ou conservadoras sobre a sociedade: a "[...] negação da 'neutralidade' profissional, registrada formalmente em 1986 através da afirmação do 'compromisso' com a 'classe trabalhadora', representou um marco fundamental no processo de ruptura com o conservadorismo profissional" (BARROCO, 2004, p. 188).

Para remar contra correntes de fragmentação do pensamento e de separação entre teoria e prática social, é fundamental não apenas subsídios metodológicos, mas uma clara postura política. Para negar um papel repressor e/ou paliativo do assistente social, é preciso tomar seu lócus de atuação - a questão social - como uma relação direta da estrutura produtiva baseada na exploração do trabalho pelo capital - e isso, ainda que de forma embrionária, representa uma posição política e teórica que coloca em xeque a ordem social burguesa (NETTO, 2005, p. 32).

\section{REFERÊNCIAS}

BARROCO, M. L. S. Serviço Social, Ética e Direitos Humanos. Revista Praia Vermelha, Rio de Janeiro, n. 11, 2004. 


\section{temporolis}

WELLEN, H.; CARLI, R. A FALSA DICOTOMIA ENTRE TEORIA

BERNSTEIN, R. Praxis and action: contemporary philosophies of human activity. Pittsburgh: University of Pennsylvania Press, 1971.

CONDORCET, Jean-Antoine. Esquisse d'un tableau historique des progrès de l'esprit humain. Paris: Garnier-Flamarion, 1988.

DURKHEIM, É. A ciência social e a ação. São Paulo: Difel, 1975.

- As regras do método sociológico. Barcarena: Editorial Presença, 2007.

ENGELS, F. Do socialismo utópico ao socialismo científico. In: MARX, Karl; ENGELS, Friedrich. Obras completas. São Paulo: Alfaômega, 1986. v. 2.

FICHTE, J. Introdução à teoria do Estado. São Paulo: Abril Cultural, 1973.

GRAMSCI, A. A concepção dialética da história. Rio de Janeiro: Civilização Brasileira, 1988.

GUERRA, Y. A instrumentalidade do serviço social. 4. ed. São Paulo: Cortez, 2005.

HELLER, A. Aristóteles y el mundo antiguo. Barcelona: Península, 1998.

LÊNIN, V. I. Sobre a cultura proletária. In: LÊNIN, V. I. Obras escolhidas em três tomos. Vol. III. São Paulo: alfa-ômega, 1980.

LOBKOWICZ, N. Theory and practice: history of a concept from Aristotle to Marx. Notre Dame: University of Notre Dame Press, 1967.

Temporalis, Brasilia (DF), ano 10, n.20, p.113-135, jul./dez. 2010. 


\section{temporolis}

WELLEN, H.; CARLI, R. A FALSA DICOTOMIA ENTRE TEORIA

LOWY, M. As aventuras de Karl Marx contra o Barão de Münchhausen: marxismo e positivismo na sociologia do conhecimento. São Paulo: Cortez, 2003.

LUKÁCS, G. História e consciência de classe. São Paulo: Martins Fontes, 2003.

- A responsabilidade social do filósofo. In: . O jovem Marx e outros escritos filosóficos. Rio de Janeiro: Editora UFRJ, 2009.

. Trata-se do Realismo! In: BARRENTO, J. (Org.). Realismo, materialismo, utopia: uma polêmica 1935 - 1940. Lisboa: Moraes, 1978.

. Realismo crítico hoje. 2. ed. Brasília: Thesaurus, 1991.

MARX, Karl. Elementos fundamentales para la crítica de la economía política (Gründrisse). México, DF: Siglo Veintiuno, 2001. V.1.

- Manifesto do Partido Comunista. In: MARX, Karl; ENGELS, Friedrich. Obras completas. São Paulo: alfa-ômega, 1990. v.1.

MARX, Karl.; ENGELS, Friedrich. A ideologia alemã. São Paulo: Boitempo, 2006.

MERLEAU-PONTY, M. As aventuras da dialética. São Paulo: Martins Fontes, 2006. (col. Tópicos). 


\section{temporolis}

WELLEN, H.; CARLI, R. A FALSA DICOTOMIA ENTRE TEORIA

NETTO, J. P. 1847: Marx contra Proudhon. In: NETTO, J. P. Marxismo impenitente: contribuição à história das idéias marxistas. São Paulo: Cortez, 2004.

- Capitalismo Monopolista e Serviço Social. 4. ed. São Paulo: Cortez, 2005.

PLATÃO. A República: [ou sobre a justiça, diálogo político]. São Paulo: Martins Fontes, 2006.

SANTOS, J. S. Neoconservadorismo pós-moderno e serviço social brasileiro. São Paulo: Cortez, 2000.

TEIXEIRA, F. Trabalho e valor: contribuição para a crítica da razão econômica. São Paulo: Cortez, 2004.

WALRAS, L. Compêndio dos elementos de economia política pura. São Paulo: Abril Cultural, 1983.

WEBER, M. Metodologia das ciências sociais. São Paulo: Cortez; Campinas: Unicamp, 1999 
